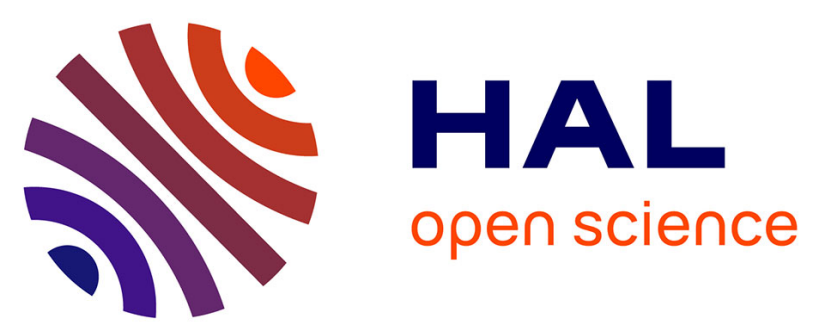

\title{
A COMPARISON OF THE REPRODUCIBILITY AND HOMOGENEITY OF AMORPHOUS Cu-Zr ALLOYS PREPARED BY ROLLER-QUENCHING AND MELT SPINNING
}

\author{
Y. Calvayrac, Mireille L. Harmelin-Vivien, A. Quivy, Jérome Chevalier, J.
}

Bigot

\section{To cite this version:}

Y. Calvayrac, Mireille L. Harmelin-Vivien, A. Quivy, Jérome Chevalier, J. Bigot. A COMPARISON OF THE REPRODUCIBILITY AND HOMOGENEITY OF AMORPHOUS Cu-Zr ALLOYS PREPARED BY ROLLER-QUENCHING AND MELT SPINNING. Journal de Physique Colloques, 1980, 41 (C8), pp.C8-114-C8-117. 10.1051/jphyscol:1980830 . jpa-00220336

\section{HAL Id: jpa-00220336 https://hal.science/jpa-00220336}

Submitted on 1 Jan 1980

HAL is a multi-disciplinary open access archive for the deposit and dissemination of scientific research documents, whether they are published or not. The documents may come from teaching and research institutions in France or abroad, or from public or private research centers.
L'archive ouverte pluridisciplinaire HAL, est destinée au dépôt et à la diffusion de documents scientifiques de niveau recherche, publiés ou non, émanant des établissements d'enseignement et de recherche français ou étrangers, des laboratoires publics ou privés. 


\section{A COMPARISON OF THE REPRODUCIBILITY AND HOMOGENEITY OF AMORPHOUS CU-ZY ALLOYS PREPARED BY ROLLER-QUENCHING AND MELT SPINNING}

Y. Calvayrac, M. Harmelin, A. Quivy, J.P. Chevalier and J. Bigot

C.E.C.M. C.N.R.S., 15, rue G. Urbain, 34400 Vitry, France

Introduction. Detailed studies have been devoted to the thermal stability of the $\mathrm{Cu}_{60} \mathrm{Zr}_{40}$ amorphous alloy $(1,2,3)$. However there are some disagreements in these descriptions. As the amorphous state is not in thermodynamic equilibrium, the reason for these disagreements may lie in the preparation procedures : Differences in quenching rate, chemical homogeneity of the samples, contamination by the crucible or by the protective atmosphere, should produce differences in the glassy state which is obtained. This paper describes experimental comparisons of the thermal behaviour of $\mathrm{Cu}_{60} \mathrm{Zr}_{40}$ amorphous samples prepared by the two methods of twinroll quenching and melt-spinning.

Experimenta1. The starting alloy ( $50 \mathrm{~g}$ ) is prepared from electrolytic copper and Kroll zirconium by levitation melting under a helium atmosphere. This ingot is then broken into small pieces ( $\sim 3 g$ ) which are melted again and twin-roll quenched or melt-spun. The twin-roll quench is performed under a helium atmosphere. For this method, levitation melting is used and prevents any contamination by a crucible. The amorphous foils are typically $20 \mathrm{~mm}$ wide and $0.1 \mathrm{~mm}$ thick. The preparation by meltspinning is generally performed in flowing helium. The alloy is melted in a silica tube. The amorphous ribbons are about $3 \mathrm{~mm}$ wide, $0.05 \mathrm{~mm}$ thick and $3 \mathrm{~m}$ long. Some ribbons have been prepared by meltspinning in air but then oxygen is incorporated in the alloy and the thermal behaviour of the amorphous ribbons is modified.

The structure of the quenched foils is examined with a step-scan X-Ray diffractometer using $C_{0} \mathrm{~K} \alpha$ radiation, and in some cases with transmission electron microscopy. DTA curves are recorded with a micro differential thermal analyser SETARAM under a $99.995 \%$ argon gas atmosphere. The sample mass is about $15 \mathrm{mg}$. The heating rate is $10 \mathrm{~K} \cdot \mathrm{min}^{-1}$.

\section{Results.}

Reproducibility of the as-quenched material.

$T a b l e s ~ I$ and II give the crystallization temperature $\mathrm{T}_{C}$, the heat of crystallization $\Delta \mathrm{H}$ and the glass transition temperature $\mathrm{T}_{\mathrm{g}}$ for a twinroll thin foil and a melt-spun ribbon respectively. A11 samples were previously determined to have no trace of cristallinity by $\mathrm{x}$-Ray diffraction. $\mathrm{T}_{\mathrm{g}}$ and $T_{c}$ are extrapolated temperatures : they are defined as the temperatures at which the extrapolated baseline intersects the steepest tangent to the peaks.

Tab1e I.

$\mathrm{T}_{g}, \mathrm{~T}_{\mathrm{C}}$ and $\Delta \mathrm{H}$ for $\mathrm{a}^{\mathrm{Cu}} 6 \mathrm{Cu}_{40} \mathrm{Z \textrm {r } _ { 4 }}$ amorphous thin foil obtained by the twin-roll quenching technique. The different samples are cut from the same foil.

\begin{tabular}{|l|lllllll|}
\hline sample & 1 & 2 & 3 & 4 & 5 & 6 & 7 \\
\hline number & 702 & 703 & 701 & 701 & 701 & 701 & 703 \\
\hline $\mathrm{T}_{\mathrm{g}}(\mathrm{K})$ & 745 & 745 & 746 & 746 & 746 & 745 & 746 \\
$\mathrm{~T}_{\mathrm{c}}(\mathrm{K})$ & 3.9 & 4.1 & 4.4 & 4.3 & 4.0 & 4.1 & 4.1 \\
$\Delta \mathrm{H}$ & & & & & & & \\
\hline
\end{tabular}

Table II.

$\mathrm{T}_{\mathrm{g}}, \mathrm{T}_{\mathrm{c}}$ and $\Delta \mathrm{H}$ for a $\mathrm{Cu}_{60} \mathrm{Zr}_{40}$ amorphous ribbon prepared by melt-spinning in helium. The different samples are cut from the same ribbon, every $40 \mathrm{~cm}$.

\begin{tabular}{|l|lllll|}
\hline $\begin{array}{l}\text { sample } \\
\text { number }\end{array}$ & 1 & 2 & 3 & 4 & 5 \\
\hline $\mathrm{T}_{\mathrm{g}}(\mathrm{K})$ & 700 & 699 & 702 & 702 & 701 \\
$\mathrm{~T}_{\mathrm{c}}(\mathrm{K})$ & 752 & 751 & 750 & 750 & 749 \\
$\Delta \mathrm{H}$ & 4.2 & 4.1 & 4.3 & 4.2 & 3.9 \\
$\left(\mathrm{~kJ} . \mathrm{mole}^{-1}\right)$ & & & & & \\
\hline
\end{tabular}

It appears that, for the same twin-roll quenched foil or the same melt-spun ribbon, the scatter in the values of $T_{g}, T_{c}$ and $\Delta H$ is smaller than the experimental accuracy $\left( \pm 3 \mathrm{~K}\right.$ for $\mathrm{T}_{\mathrm{g}}$ and $\mathrm{T}_{\mathrm{c}}$, $\pm 6 \%$ for $\Delta \mathrm{H}$ ). 
Results show considerably more scatter if the samples are chosen in different ribbons, obtained by different quenches (Table III). Moreover a careful examination of DTA curves shows that the relative temperatures of the end of the glass transition $\mathrm{T}_{\mathrm{g}_{\mathrm{f}}}$ and the cristallization temperature $T_{c}$ vary significantly from sample to sample. ${ }^{(} \mathrm{T}_{\mathrm{g}_{\mathrm{f}}}$ is defined as the temperature at which the specific heat $C_{p}$ attains its higher value).

Table III.

Thermal characteristics of different melt-spun ribbons.

\begin{tabular}{|c|c|c|c|c|c|c|c|}
\hline $\begin{array}{l}\text { Sample } \\
\text { number }\end{array}$ & $\underset{(K)}{T_{g}}$ & $\underset{(\mathrm{K})}{\mathrm{T}_{\mathrm{g}_{f}}}$ & $\begin{array}{l}\Delta \mathrm{C}_{\mathrm{p}} \times 10^{3} \\
\left(\mathrm{KJ} \cdot \mathrm{mole}^{-1} \cdot \mathrm{K}^{-1}\right)\end{array}$ & $\begin{array}{l}T_{C} \\
(K)\end{array}$ & $\begin{array}{l}\Delta \mathrm{H} \\
\mathrm{kJ} \cdot \mathrm{mole}^{-1}\end{array}$ & $\begin{array}{l}T_{c}^{-T} g \\
(K)\end{array}$ & $\underset{(K)}{\mathrm{T}_{c}-\mathrm{T}_{\mathrm{f}}}$ \\
\hline 1 & 708 & 731 & 22 & 756 & 4.3 & 48 & 25 \\
\hline 2 & 703 & 723 & 21 & 746 & 4.3 & 43 & 23 \\
\hline 3 & 701 & 723 & 23 & 746 & 4.1 & 45 & 23 \\
\hline 4 & 702 & 723 & 21 & 744 & 4.1 & 42 & 21 \\
\hline 5 & 702 & 723 & 20 & 743 & 4.1 & 41 & 20 \\
\hline 6 & 705 & 725 & 19 & 742 & 4.1 & 37 & 17 \\
\hline 7 & 701 & 720 & 16 & 737 & 4.0 & 36 & 17 \\
\hline 8 & 698 & 720 & 19 & 736 & 4.1 & 38 & 16 \\
\hline 9 & 698 & 718 & 15 & 734 & 4.0 & 36 & 16 \\
\hline 10 & 699 & 718 & 17 & 734 & 4.3 & 35 & 16 \\
\hline
\end{tabular}

Along a given amorphous ribbon (i.e. for a given quench) the $\left(\mathrm{T}_{c}{ }^{-T} \mathrm{~g}_{f}\right)$ interval remains constant. Ten different ribbons have been prepared on the same day and immediately examined to prevent any difference in temperature-time history. On figure 1 the beginning of their crystallization exotherms have been plotted taking $I_{g_{f}}$ as time origin : An increase in $\left(\mathrm{T}_{c}{ }^{-\mathrm{T}} \mathrm{g}_{f}\right)$ from sample 10 to sample 1 clearly appears. Table III shows that corresponding increases occur in $\left(\mathrm{T}_{\mathrm{c}}-\mathrm{T}_{g}\right)$ and $\mathrm{T}_{g}$ values. The thermal stability of glasses is often measured as the difference between $T_{c}$ and $T_{g}(4)$ : More stable glasses have larger $\left(T_{c}-T_{g}\right)$ values. The differences in thermal stability of the ten ribbons are confirmed by the resuits of isothermal annealing experiments near $T_{g}$ : the volume fraction of crystalline material formed on annealing at $693 \mathrm{~K}$ for 40 hours varies from $0 \%$ for sample 1 to $83 \%$ for sample 10 .

Similar experiments on twin-roll quenched foils show that the reproducibility is the same for twin-roll quenched foils as for melt-spun ribbons. The variation in thermal stability from sample to sample may be explained by differences in cooling rates, in contamination, or in composition, An effect of composition may occur, due to compositional fluctuations between the $\sim 3 \mathrm{~g}$ alloy pieces

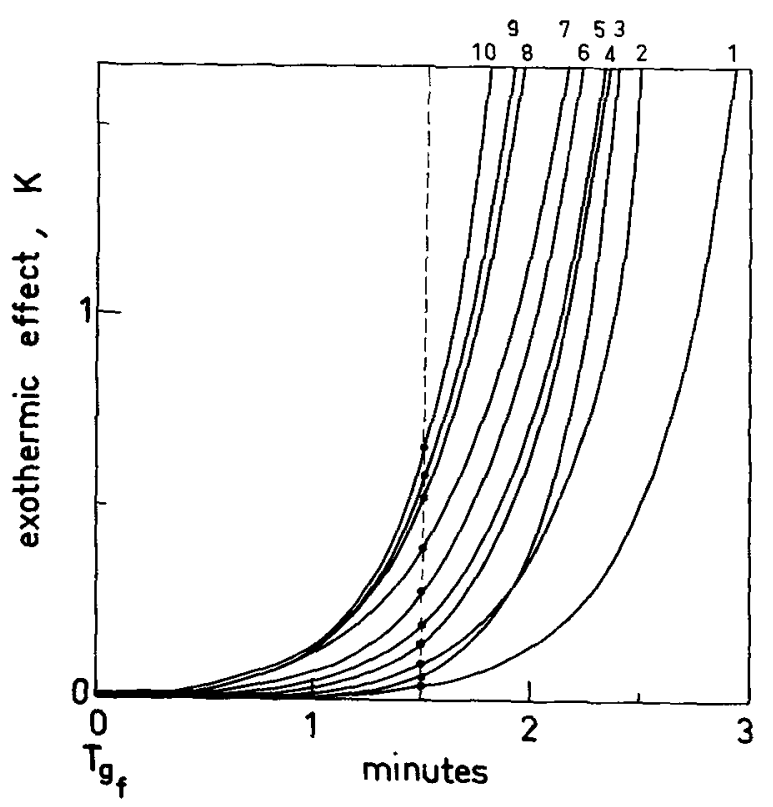

FIG. 1. - Beginning of the crystallization exotherms for ten melt-spun ribbons. All the samples had the same mass ( $14.5 \mathrm{mg}$ ). Time is counted starting from $\mathrm{T}_{\mathrm{g}_{\mathrm{f}}}$. The heating rate was $10 \mathrm{~K} \cdot \mathrm{min}^{-1}$. 
chipped from the starting ingot and then used for quenching from the melt. However the study of Kerns (2) on the effect of composition on the thermal characteristics of $\mathrm{Cu}-\mathrm{Zr}$ amorphous alloys shows that an increase $\Delta \mathrm{T}_{\mathrm{c}}$ of $20 \mathrm{~K}$ corresponds to a change of 4 atomic $\% \mathrm{zr}$. It is unlikely that such inhomogeneities exist in the starting ingot, prepared by levitation melting.

Effect of oxygen contamination.

Effects of surface contamination are readily observed :

- Amorphous $\mathrm{Cu}_{60} \mathrm{Zr}_{40}$ alloys undergo change in surface colour when kept in air for several days.

- The atmosphere in the DTA (pure argon) is not sufficiently clean to prevent oxidation of the amorphous samples during the runs and some

"blackening" of the surface is visible to the eye.

These surface effects are accompanied by the occurrence, on the X-ray diffraction pattern, of a narrow diffraction line superimposed on the beginning of the first broad peak characteristic of the amorphous structure. This line (seen at $2 \theta \sim 35^{\circ}$ when Co radiation is used) is due to metastable (cubic or tetragonal) $2 \mathrm{rO}_{2}$. After longer annealing times under pure argon, at temperatures well below $\mathrm{T}_{g}$, this line becomes more intense and a diffraction pattern corresponding to monoclinic $\mathrm{ZrO}_{2}$ appears, together with the diffraction pattern of Cu. All these lines disappear upon a 1ight polisting of the surface: It only remains the diffraction pattern characteristic of the $\mathrm{Cu}_{60} \mathrm{Zr}_{40}$ amorphous phase.

In order to observe some effect of oxidation on the DTA curves, two amorphous samples were annealed at $413 \mathrm{~K}$ for 7 days, one in air and the other in ultra-high vacuum. The corresponding DTA curves are shown on figure 2 .

The lower curve, obtained after annealing in air, shows the occurrence of a second exothermic peak. Moreover, a decrease in the temperature of the onset of crystallization and a decrease in $\left(\mathrm{T}_{c}-\mathrm{T}_{g}\right)$ are clearly seen : Contamination by annealing in air leads to a decrease in thermal stability. Similar heat-treatments in pure argon induce similar effects on the DTA curves : a second exothermic peak appears and it increases with annealing time.

In their detailed study of the crystallization of amorphous $\mathrm{Cu}_{60} \mathrm{Zr} 40$ alloy, Vitek et al. (1) report that samples previously isothermally annea-

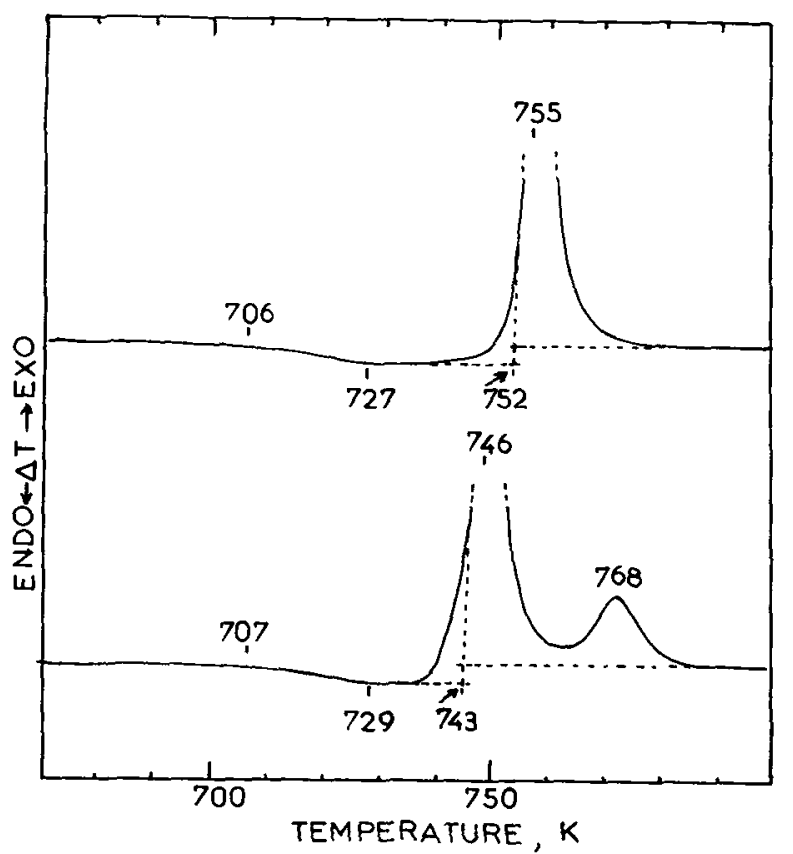

EIG. 2. - DTA curves for amorphous $\mathrm{Cu}_{60} \mathrm{Zr} 40$ alloys, after annealing at $413 \mathrm{~K}$ for 7 days in ultra-high vacuum (upper curve) or in air (lower curve).

led below the crystallization temperature exhibit two exothermic reactions. As annealing is performed in a DTA under an argon atmosphere, contamination during annealing is suggested. Vitek proposes that the first exothermic peak corresponds to the crystallization of the initial amorphous structure and the second peak corresponds to the crystallization of a "transformed amorphous structure". He follows the annealing behaviour by transmission electron microscopy. When crystallization has been initiated, he finds regions in the foils the electron diffraction pattern of which exhibits two broad halo rings, that corresponding to the initial amorphous matrix and a second one, at a larger d spacing, corresponding to the "transformed amorphous matrix". We have observed our amorphous samples by transmission electron microscopy. Figure $3 a$ ) is an electron diffraction pattern of an amorphous foil observed immediately after thinning. This thinned foil was kept in air for three months and observed again. Figure $3 b$ ) is the corresponding diffraction pattern : a broad inner halo is seen, at $k$ values correspondingtothe (111) reflection of cubic $\mathrm{ZrO}_{2}$ mentioned above. Thus it is believed that the "transformed amorphous phase" observed by Vitek is an amorphous $\mathrm{Cu}-\mathrm{Zr}$ phase 
rich in oxygen. In the samples studied by Vitek this phase is likely to be formed during annealing in argon.
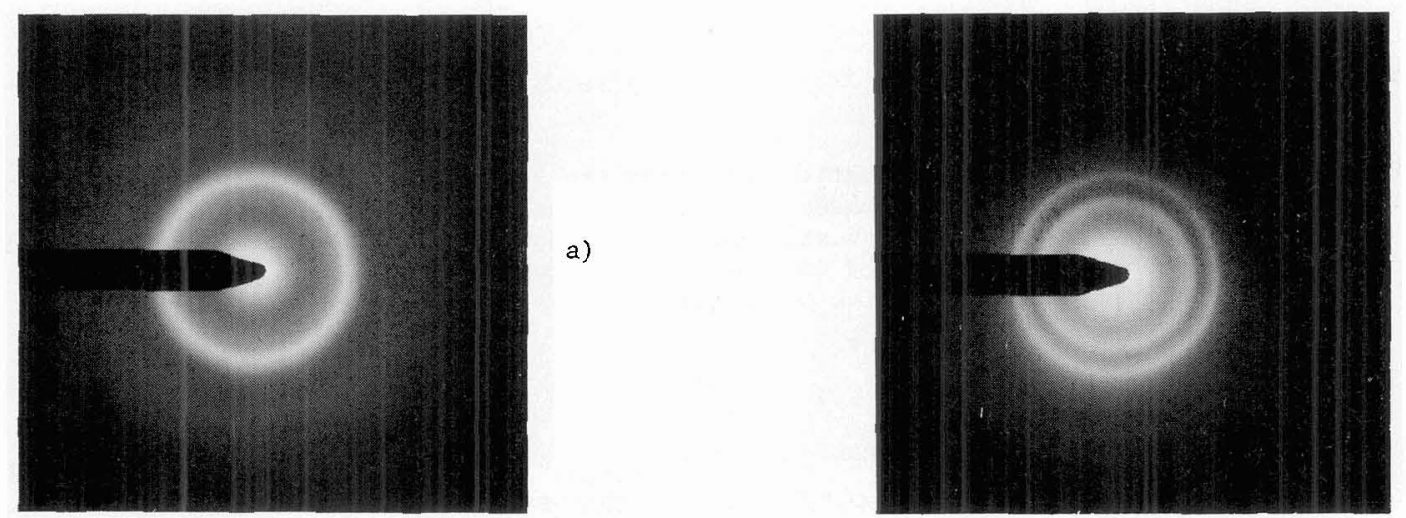

b)

FIG. 3 - Electron diffraction patterns of an amorphous $\mathrm{Cu}_{60} \mathrm{Zr}_{40}$ foil.

a) observed immediately after thinning.

b) kept in air for three months and observed again.

We have followed the behaviour of the DTA curves as a function of previous isothermal annealing in the temperature range $673-713 \mathrm{~K}$ studied by Vitek. The heat-tretments were performed in ultra-high vacuum. In these conditions crystallization occurs by a single exothermic reaction. $\mathrm{X}$-ray data show that the equilibrium crystalline phase is formed. Figure 4 illustrates the beginning of crystallization, as detected by X-ray diffraction. The presence of a weak $\mathrm{ZrO}_{2}$ line is pointed out.

Thus, from this study it appears that very carefully controlled conditions must be achieved for the preparation as for the characterization of amorphous $\mathrm{Cu}-2 \mathrm{r}$ alloys. In these conditions, amorphous samples prepared by twin-roll quenching or by melt-spinning do not show any significant differences in their thermal behaviour.

\section{References.}

(1) Vitek, J.M., Vander Sande, J.B., and Grant, N.J., Acta Met. 23 (1975) 165.

(2) Kerns, A.J., Ph.D., Northeastern University (1974).

(3) Kerns, A.J., Polk, D.E., Ray, R., and Giessen, B.C., Mater. Sci. Eng. 38 (1979) 49.

(4) Polk, D.E., and Chen, H.S., J. Non-Crystalline Solids 5 (1970) 1.

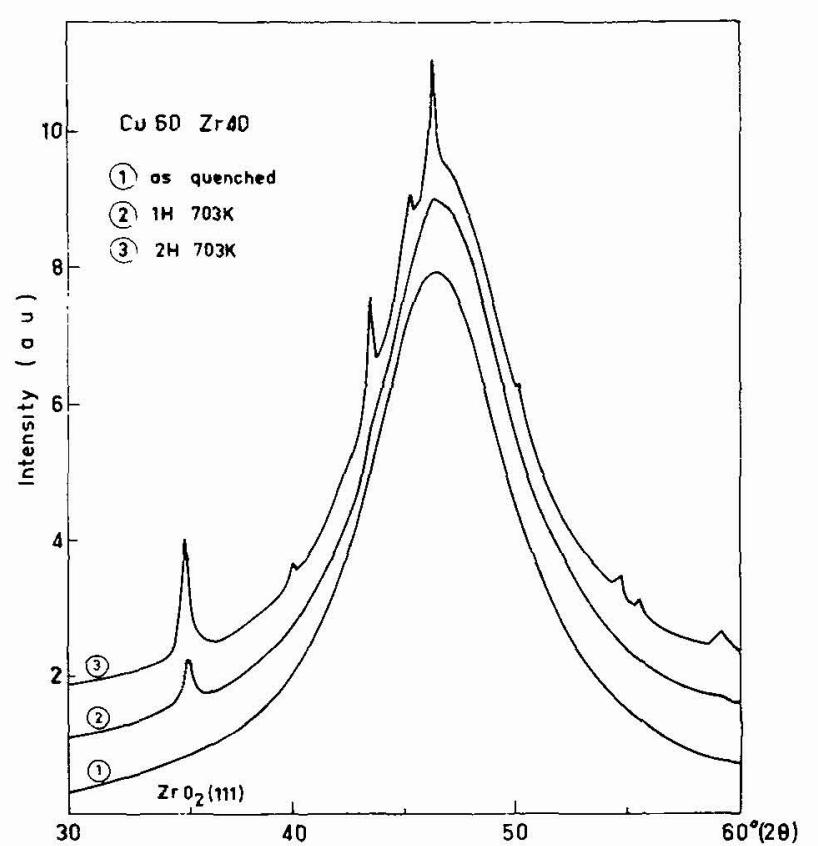

FIG. 4. - X-ray diffraction patterns (Co $K \alpha$ radiation) for a $\mathrm{Cu}_{60} \mathrm{Zr}_{40}$ sample. Curves (2) and (3) are shifted for more clarity. A beginning of crystallization is detected after isothermal annealing at $703 \mathrm{~K}$ for 1 hour (curve (2)). 